\title{
Not all asthma inhalers are the same: factors to consider when prescribing an inhaler
}

\author{
*Henry Chrystyna, David Price ${ }^{a}$
}

a Department of Pharmacy, University of Huddersfield, School of Applied Sciences, Queensgate, Huddersfield, West Yorkshire, UK

b Department of General Practice and Primary Care, University of Aberdeen, Aberdeen, Scotland, UK

Received 14th October 2008; revised version received 19th January 2009; accepted 22nd February 2009; online 9th June 2009

\begin{abstract}
National and international asthma guidelines stress that before making changes to patients' therapy their compliance and inhaler technique should be checked. This review addresses these issues and highlights the differences between inhalers in terms of inhaler technique, individual ability/competence, and ease of use. The advantages and disadvantages of metered-dose inhalers (MDIs) and dry powder inhalers (DPIs) are presented. The reformulation of beclometasone MDIs is discussed since there has been some confusion over prescribing and Regulatory Authorities have recommended that these should be prescribed by brand name and not generically. This review should provide prescribers with an update to help them appreciate the differences between inhalers thereby optimising each patient's inhaled treatment.
\end{abstract}

(c) 2009 General Practice Airways Group. All rights reserved.

H Chrystyn and D Price. Prim Care Resp J 2009; 18(4): 243-249

doi:10.4104/pcrj.2009.00029

Keywords asthma, inhalers, inhalation technique, compliance, CFC-Free MDI, DPI

\section{Contents}

Abstract

Introduction

Optimise the inhaler for the patient

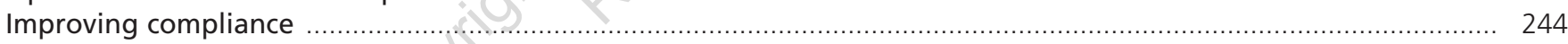

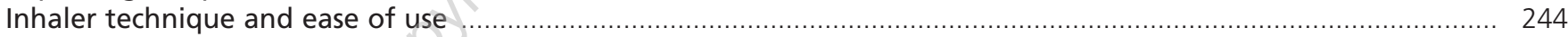

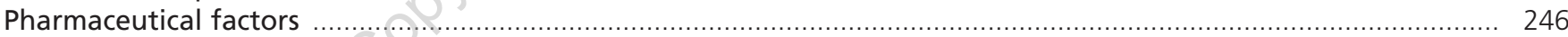

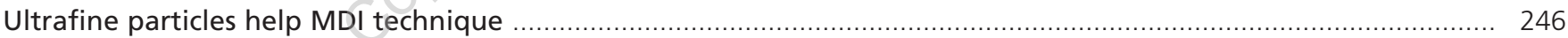

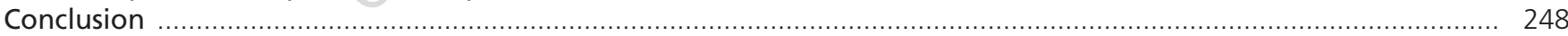

\section{Introduction}

Numerous therapeutic advances, an unprecedented understanding of asthma's pathophysiology and immunology, and comprehensive asthma guidelines, ${ }^{1,2}$ have helped support better asthma management over the past decade, with falling prevalence trends. ${ }^{3}$ Yet despite these improvements there remains considerable - and often potentially avoidable residual morbidity and mortality among people with asthma. ${ }^{4-6}$ Asthma guidelines recommend increasing therapy for poorly controlled symptoms and checking the patient's compliance and inhalation technique before any therapeutic changes are made. If these recommendations are followed, there are around $5 \%$ of asthma cases that prove difficult to control despite using maximal doses of inhaled medications. ${ }^{\text {? }}$

In accordance with guidelines and a recently-published International Primary Care Respiratory Group (IPCRG) position paper, $^{8}$ before altering the therapeutic management of a patient with asthma the following key questions should be answered and addressed:

- Is the patient complying with their prescribed medication?

- Has the most appropriate inhaler device been chosen for the individual patient?

\footnotetext{
* Corresponding author: Professor Henry Chrystyn, Department of Pharmacy, University of Huddersfield, School of Applied Sciences, Queensgate, Huddersfield, West Yorkshire, HD1 3DH, United Kingdom. Tel: 01484472783 Fax: 01484472182 E-mail: h.chrystyn@hud.ac.uk
} 
- Can the patient use the inhalation technique recommended by the manufacturer?

- Has smoking cessation been adequately encouraged if applicable?

- Has management of concurrent conditions such as rhinitis been maximised?

In this article, we will look specifically at compliance and the inhaler device with particular emphasis on inhalation technique.

\section{Optimise the inhaler for the patient}

BTS/SIGN ${ }^{1}$ and GINA $^{2}$ guidelines form the foundation of asthma management and "appear to be the best vehicle available to assist primary care physicians and patients to receive the best possible care of asthma". ${ }^{2}$ However, guidelines cannot accommodate inter-subject variations in response to treatment or individual patients' needs and preferences. Furthermore, guidelines are not equipped to address the problem of inhaler misuse. ${ }^{10}$ Using guidelines as the foundation, it is therefore the responsibility of healthcare professionals to build upon this framework in order to optimise inhaler use for each individual asthma patient.

According to meta-analyses, as long as patients use the correct technique, the various drug delivery devices used in asthma produce similar outcomes.11,12 The majority of the studies included in these meta-analyses evaluated inhaled bronchodilator use, ${ }^{12}$ and they included patients highly trained to use each device and excluded them if they could not use the appropriate optimal inhalation technique. During routine practice this does not occur.

In practice, when using an inhaled bronchodilator, if symptom relief is not as expected then it is usual to inhale another dose. This immediate feedback is a sign that the patient's asthma control is deteriorating or that their inhalation technique needs to be checked. Inhaled corticosteroids (ICS) do not provide this feedback and so if the patient's technique is not correct their control will deteriorate over time. Hence, feedback on reliever use is a good indicator that the patient's inhalation technique needs to be checked and if necessary their inhaler changed to one they can use more easily.

To optimise inhaler use, healthcare professionals need to consider the interaction between the inhaler, drug and patient when instigating treatment (to prevent problems), and when managing patients who present with inadequately controlled symptoms. Since all the drugs used are safe and effective then the most important considerations are compliance, device and technique. Given equivalent effectiveness, acceptability and safety then healthcare professionals should prescribe the least costly product that is suitable for the patient. ${ }^{13}$
In acute situations, nebulisers can be used and if possible should be driven by oxygen. However most nebulisers are noisy, bulky, require a compressor and electricity, and are very inefficient methods to deliver a dose to the lungs. In acute situations, spacers attached to an MDI are as useful, ${ }^{14}$ with five separate doses of salbutamol equivalent to $5 \mathrm{mg}$ of nebulised salbutamol. ${ }^{15}$ If a spacer is not available then a plastic cup or bottle in place of a spacer is a useful alternative.

\section{Improving compliance}

Poor compliance is common among people with asthma. Non-compliance rates vary from $16 \%$ to $50 \%$ and there is no doubt that this problem poses a real clinical issue. ${ }^{13}$ During regular reviews, almost a third of asthma patients reported not taking their prophylactic medication as prescribed. ${ }^{16}$ In other studies, half of patients underused their asthma medication, ${ }^{17}$ and even the $50 \%$ of people with difficult-tocontrol asthma were not compliant with oral corticosteroids. ${ }^{7}$

Even conservative estimates indicate that poor compliance makes an important contribution to the morbidity, mortality and expense associated with asthma. Each 25\% increase in the proportion of time without ICS is associated with double the hospitalisation rate for asthma, and poor compliance appears to contribute to $61 \%$ of deaths from asthma. ${ }^{18}$

Addressing the multi-factorial issues underlying poor compliance is challenging and there are few well-designed studies to guide healthcare professionals. Nevertheless, several approaches can help improve compliance including:

- Understanding, recognising and responding to patients' perspectives on asthma and its treatment. ${ }^{19}$ As many as one in five patients report concerns about ICS or question the need for their use. Healthcare professionals therefore need to adopt a non-judgemental approach, clearly explaining why the patient needs ICS, as well as addressing any concerns surrounding key issues such as long-term side effects, dependence and medication use. ${ }^{18,19}$

- Emphasising the benefits of therapy

- Offering simple, clear instructions

- Recognising and responding to patient partiality - i.e. choosing therapy in line with their preferences.

Overall, patient education has been shown to improve compliance with ICS. ${ }^{20}$ Also, patients with asthma tend to prefer the inhalers they find the easiest to use. A comparison of seven inhalers found that $30 \%$ of children with asthma rated the Easi-Breathe ${ }^{\circledR}$ (a breath-actuated MDI) as their first choice. In addition, a spacer attached to a MDI was the leastpreferred inhalation method. ${ }^{21}$

\section{Inhaler technique and ease of use}

Many patients experience problems using their devices correctly. An MDI should be used with an inhalation that is 


\begin{tabular}{|c|c|c|}
\hline \multirow[t]{2}{*}{ Error } & \multicolumn{2}{|c|}{ per cent of patients } \\
\hline & MDI & \\
\hline Failure to co-ordinate actuation and inhalation & 27 & - \\
\hline Inadequate or no breath hold after inhalation & 26 & 23 \\
\hline Too rapid inspiration / not inhaling forcibly & 19 & 17 \\
\hline Inadequate shaking / mixing before use & 13 & - \\
\hline Cold Freon effect & 6 & - \\
\hline $\begin{array}{l}\text { Actuation at total lung capacity / Not exhaling } \\
\text { to residual volume before inhaling }\end{array}$ & 4 & 24 \\
\hline Multiple actuations during single inspiration & 3 & - \\
\hline Inhaling through nose during actuation & 2 & - \\
\hline $\begin{array}{l}\text { Exhaling during activation / through the } \\
\text { mouth piece }\end{array}$ & 1 & 19 \\
\hline Putting wrong end of inhaler in mouth & $<1$ & - \\
\hline Holding device in wrong position / incorrectly & $<1$ & 35 \\
\hline Exhaling into the mouth piece after inhalation & - & 20 \\
\hline
\end{tabular}

slow and deep whereas when using a DPI the inhalation should be as deep and hard as possible. However, it is not clear how patients and healthcare professionals interpret or understand these generic instructions. On most occasions the inhalation flow of patients through an MDI is faster than a DPI. ${ }^{22}$ Using any inhaler means performing a number of steps correctly and in the right order, and patients often make mistakes. Even healthcare professionals are often not able to use inhalers effectively. ${ }^{23}$

Poor inhaler technique can markedly reduce the proportion of drug that reaches the lung. In one large study, $70 \%$ of 3955 patients misused MDIs, with almost half of all cases being due to poor co-ordination. ${ }^{24}$ Other studies suggest that between $32 \%$ and $96 \%$ of patients commit errors when using MDIs, with $28-68 \%$ not even using their MDI or DPI sufficiently well to benefit from the drug. ${ }^{25}$ Table 1 summarises the range of problems patients have with the use of these inhalers. ${ }^{25-28}$

(a) Metered-Dose Inhalers (MD/s)

A recent report has highlighted that during routine use only $7.6 \%$ of asthmatics could use an MDI with a slow and deep inhalation and with good co-ordination. ${ }^{29}$ Poor co-ordination between actuation and inhalation - one of the most common mistakes with MDIs - reduces lung deposition to $7.2 \%$. This compares with figures of $22.8 \%$ and $20.8 \%$ for those correctly taught how to use the MDI and the Autohaler (a breath-actuated MDI), respectively. ${ }^{30}$

The most common mistake made by patients using a MDI is that they inhale too fast. ${ }^{29}$ In a study of asthmatic patients using MDls, those who inhaled slowly (30 L/min) and then held their breath for 10 seconds showed the greatest drug deposition in the lung, including both the tracheobronchial and alveolar regions. Lung deposition was not affected when dose actuation was delayed until an inhalation started. ${ }^{31}$ Hence when using a slow inhalation it is not essential to coordinate dose release from an MDI with the start of the inhalation as long as the inhalation is slow and starts before the dose emission. The slow and deep inhalation translates into a slow vital inspiratory capacity manoeuvre. Since this volume is normally about 2.5 litres then if the inhalation manoeuvre takes five seconds the inhalation flow will be 30 $\mathrm{L} / \mathrm{min}$. It may, therefore, be practical to train patients to inhale over five seconds when using their MDI.

Overall, the issue of correct use is of critical importance in maintaining optimal asthma control since patients who misuse MDIs tend to have less stable asthma than those who use their device correctly. ${ }^{24}$ Healthcare professionals can offer advice and education to help improve inhaler technique in various settings. ${ }^{32,33}$ Recent research also suggests that training aids, such as the 2 Tone Trainer $^{\circledR}$ (Canday Medical, UK) can improve $\mathrm{MDI}$ technique by ensuring that a slow inhalation is used. The overall effect when giving patients a 2Tone trainer was a clinically significant increase in asthma quality of life. ${ }^{29}$

Choosing a device preferred by patients (due to its ease of use) can help optimise actual disease control. For example, patients using the preferred Easibreathe device achieved greater asthma control than with an MDI, resulting in fewer GP consultations for their asthma. ${ }^{34}$ In a key analysis of the DIN-LINK database of UK general practices, which compared outcomes among 7412 patients using traditional and breathactuated MDIs to deliver ICS, breath-actuated MDIs appeared to improve outcomes; patients using breath-actuated MDIs were prescribed $25 \%$ less short-acting $\beta_{2}$-agonist, used up to $64 \%$ per cent less oral steroid, and up to $44 \%$ less antibiotics, than their counterparts using traditional MDIs. ${ }^{34}$ If patients cannot use an MDI correctly after instruction and education they should be switched to a different device. If they are happy with an MDI then a breath-actuated MDI is the most convenient choice.

Spacers used with MDIs compensate for problems with coordination and decrease the incidence of any local effects in the mouth caused by oropharyngeal impaction of the drug during inhalation. Spacers also improve lung deposition. Due to static problems only one dose should be used per inhalation and they should be washed in detergent and allowed to dry. However, spacers are not easily portable and are least preferred by patients. ${ }^{20}$ In general, there is little difference between small and large spacers. ${ }^{35}$

(b) Dry Powder Inhalers (DPIs)

A DPI should be inhaled with a fast suck that is as deep and hard as possible. The patient's inhalation flow interacts with the resistance inside the DPI to generate a turbulent energy which de-aggregates the formulation into an emitted dose containing particles that have the potential for lung 
deposition. ${ }^{36}$ As the dose leaves its metering cup inside the DPI during the first few milliseconds of the inhalation manoeuvre, then the fast inhalation should occur immediately. Failure to achieve a fast inhalation at the beginning results in the emission of particles that are too big to be deposited into the lungs and so these are only deposited in the mouth. ${ }^{37}$ Many patients are unaware that the fast inhalation should start immediately and those patients that gradually accelerate their inhalation flow to a fast rate should be re-trained.

All DPIs have a different internal resistance ${ }^{36}$ that decreases the inhalation flow used by a patient. Since the turbulent energy is a product of the flow and the inhaler's resistance then for a set energy level the flow required through a low resistance DPI will be faster than that of a high resistance DPI. The faster the inhalation flow through a DPI then the greater will be the turbulent energy. Hence all DPIs have flowdependent dose emission with some DPIs more prone to this than others. ${ }^{36}$ However, the clinical significance of this is not proven. In general, DPIs with a high resistance provide greater lung deposition than those with a low resistance..$^{38}$

There is a minimum threshold energy required at which the de-aggregation is sufficient to provide a dose with the potential to produce particles with the required size. It is generally accepted that this minimum threshold energy is equivalent to an initial inhalation flow of $30 \mathrm{~L} / \mathrm{min}$ through a DPI. The higher the resistance then the lower will be the minimum flow and vice versa, as shown from studies on the Turbuhaler. Therefore, similar values would apply for DPIs with a similar resistance to the Turbuhaler such as a Clickhaler. DPIs with a higher resistance (Easyhaler) would require alower flow whilst those with a lower resistance (Accuhaler and Novolizer) would require a faster inhalation flow.

Studies have highlighted that some patients have problems achieving a fast inhalation rate during routine use with a DPI. ${ }^{36,39-42}$ These studies have revealed that young children and those with severe airway obstruction are most likely to have problems using a fast inhalation flow. Since DPIs are very much dependent on the achievement of a certain inspiratory flow rate, there is a risk of reduced efficacy during episodes of acute wheeze or in patients with low pulmonary function. ${ }^{41,42}$ In general, DPIs with a low resistance are more prone to this reduction than those with a high resistance. ${ }^{43}$

\section{Pharmaceutical factors}

The pharmaceutical industry has responded to the challenge to reformulate ICS inhalers because of the ban on the chlorofluorocarbon (CFC) propellants used in MDIs. Most have been formulated with hydrofluroalkane propellants (HFAs) although a few CFC-based generic beclometasone MDIs are still available. Traditionally, corticosteroid CFC MDIs were a suspension of particles, but to overcome stability issues between the particles (especially beclometasone) some HFA ICS formulations have been formulated as solution aerosols and two different approaches have been used. Some formulations provide a product that emits ultrafine particles from a solution aerosol. This improves lung deposition and the resulting increase in efficacy enables the drug dose to be halved. ${ }^{44,45}$ The proportion of the dose delivered that reaches the lung from MDI devices such as Qvar ${ }^{\circledR}$ (ultra fine beclometasone, Teva) and ciclesonide (Alvesco ${ }^{\oplus}$, Nycomed) is around $50-60 \% .{ }^{46,47}$ More recently a combination of beclometasone with formoterol in an MDI has been introduced. This MDI, called Fostair ${ }^{\circledast}$ (Trinity Chiesi), also emits ultrafine beclometasone particles with a resultant high lung deposition compared to traditional MDIs. ${ }^{48}$ The other advantages of ultrafine particles are that the drug is distributed throughout the airways with good penetration of corticosteroid into the smaller airways ${ }^{46}$ and that lung deposition is less affected by any variability in the inhalation flow used by the patient. ${ }^{49}$ Furthermore, if lung deposition is high then less is deposited in the mouth and throat.

Others have altered the formulations of the solution aerosols to reduce the quality of the emitted dose such that the emitted particles are similar to those of the CFC formulations. The result is that lung deposition is as inefficient as the CFC $\mathrm{MDI}$ formulations and the oropharyngeal deposition is high but the prescription is a dose-for-dose transition.

At present there are two different beclometasone HFA MDIs available. Qvar ${ }^{\circledast}$ is the formulation that emits ultrafine particles and hence has been shown to provide efficient lung deposition with similar efficacy to the traditional CFC beclometasone MDI but at half the dose. In contrast, Clenil ${ }^{\oplus}$ (Chiesi) has been formulated to mimic the dose emission characteristics of the traditional beclometasone CFC MDI formulation, and since the lung deposition of the traditional CFC MDI is low then the lung deposition from Clenil is not as efficient as that with Qvar ${ }^{\oplus}$. Hence, Qvar ${ }^{\oplus}$ will provide the same efficacy with the same safety profile as Clenil but at half the dose. As a result, the Medicines and Healthcare products Regulatory Agency (MHRA) has asked prescribers to state the brand, rather than prescribing CFC-free propellant beclometasone MDIs generically.

Around one in 10 patients will stop inhaling or breathe through their nose when the cold CFC hits the back of their throat, which may further reduce lung deposition. ${ }^{26}$ This is known as the cold-Freon effect. The aerosol released from an HFA MDI is warmer and the velocity is slower than from a CFC $M D I,{ }^{50}$ and thus it has the potential to help prevent the coldFreon effect experienced by some patients.

\section{Ultrafine particles help MDI technique}

In practice, many patients revert to their usual incorrect MDI 
Not all inhalers are the same

Table 2. Advantages and disadvantages of inhaler devices for asthma.

\begin{tabular}{|c|c|c|}
\hline Type & Advantages & Disadvantages \\
\hline Traditional MDI & $\begin{array}{l}\text { Portable and compact } \\
\text { Short treatment time } \\
\text { No preparation } \\
\text { No contamination risk } \\
\text { High reproducibility between doses }\end{array}$ & $\begin{array}{l}\text { Coordination of breathing and actuation needed } \\
\text { Most patients inhale too fast } \\
\text { Inefficient lung deposition } \\
\text { High oro pharyngeal deposition } \\
\text { Only one has a dose counter } \\
\text { The number of remaining doses may be difficult to determine } \\
\text { Important to shake before user } \\
\text { Limited range of breath actuated MDIs } \\
\text { Short shelf life with formoterol MDI }\end{array}$ \\
\hline $\begin{array}{l}\text { MDI emitting } \\
\text { ultrafine particles }\end{array}$ & $\begin{array}{l}\text { High lung deposition } \\
\text { Lower oro-pharyngeal deposition } \\
\text { Good for inhaled corticosteroids } \\
\text { Less importance for an optimal } \\
\text { inhalation technique } \\
\text { Reduced need to use spacers } \\
\text { Reduced need to use breath actuated } \\
\text { MDls (however one is available and } \\
\text { would help if co-ordination is } \\
\text { 'hopeless') }\end{array}$ & $\begin{array}{l}\text { Only two corticosteroid products available (Qvar and Alvesco) } \\
\text { Only one combination product available (Fostair) - short shelf life due } \\
\text { to formoterol } \\
\text { No dose counter } \\
\text { Inhalation of ultrafine particles is still a new concept } \\
\text { Spacers may be required if oral side effects occur } \\
\text { The corticosteroid dose has to be halved if prescribed for patients } \\
\text { previously using other traditional corticosteroid MDI products }\end{array}$ \\
\hline Spacers & $\begin{array}{l}\text { Less need for co-ordination than an MDI } \\
\text { Reduced oropharyngeal deposition } \\
\text { compared to MDI } \\
\text { Improves lung deposition if poor } \\
\text { Good during acute exacerbations } \\
\text { Can use tidal breathing if the spacer has } \\
\text { a valve (for example Volumatic and } \\
\text { Aerochamber) } \\
\text { The Aerochamber makes a noise if the } \\
\text { inhalation flow is too fast }\end{array}$ & $\begin{array}{l}\text { Some patients find inhalation more complex and the dose can be lower } \\
\text { if not used correctly } \\
\text { More expensive and less portable than MDI alone } \\
\text { Prone to static } \\
\text { Special washing instructions } \\
\text { Patients must discharge only one dose into the chamber before an } \\
\text { inhalation } \\
\text { Not preferred by patients }\end{array}$ \\
\hline DPI & $\begin{array}{l}\text { Breath-actuated and so no need for } \\
\text { patient coordination required } \\
\text { No propellant } \\
\text { Most have dose counters } \\
\text { Short treatment time } \\
\text { Small and portable }\end{array}$ & $\begin{array}{l}\text { Some are single dose } \\
\text { Some need to be shaken before use } \\
\text { Flow dependent dose emission } \\
\text { Needs a fast acceleration rate at the start of the inhalation } \\
\text { Poor quality (or no) dose emitted if inhalation flow is too slow } \\
\text { Uncertainty of dose emission during acute exacerbations } \\
\text { Can result in high oro-pharyngeal deposition } \\
\text { Must be upright when preparing the dose for inhalation. Must be kept } \\
\text { upright or turned horizontally for inhalation } \\
\text { More expensive than MDIs } \\
\text { Need to be stored in a cool and dry place. }\end{array}$ \\
\hline
\end{tabular}

technique when they leave the clinic. ${ }^{51} \mathrm{~A}$ recent study has shown that ultrafine particles not only improve lung deposition, but provide similar lung deposition when inhaled with a slow and a fast inhalation flow. ${ }^{49}$ The problem of patients reverting to a faster inhalation flow with an MDI after training has finished ${ }^{51}$ can therefore be solved by using an MDI that emits ultrafine particles. Furthermore, the smaller particles that are emitted contribute to improved lung deposition with good penetration throughout all the airways $^{49}$ thus maximising effective suppression of the inflammation that occurs in the small airways. ${ }^{52}$

Finally when using a product that emits ultrafine particles (such as the Qvar ${ }^{\circledR}$ and ciclesonide MDIs) oropharyngeal impaction is much lower. It has also been shown that when using an MDI that emits ultrafine particles split second coordination is not important; in one study, ${ }^{46}$ lung deposition following actuation before ( 0.5 seconds early) and after ( 1.5 seconds late) the start of the inhalation was $37 \%$ and $50 \%$, respectively, compared to $60 \%$ with good co-ordination. Usual lung deposition from other corticosteroid MDIs is 
usually less than $15 \% .{ }^{53}$ Thus, inhalation technique and oropharyngeal co-ordination are not as important for devices emitting ultrafine particles as they are for other MDIs.

\section{Conclusion}

A summary of the advantages and disadvantages of inhaler devices is presented in Table 2. Carefully choosing the most appropriate inhaler device can maximise asthma management and optimise overall clinical outcomes. Healthcare professionals should consider these issues before changing the dose of ICS or adding other treatments to the regimen of patients poorly controlled at any particular step of the guidelines. Consideration should be given to those inhalers which are least affected by the inhalation method used by the patient and those with more efficient lung deposition with reduced oropharyngeal impaction; MDIs that emit ultrafine corticosteroid particles provide efficient and even lung deposition together with lower oro-pharyngeal deposition without the use of a spacer, and using an optimal inhaler technique is less important than when using a traditional MDI.

\section{Conflict of interest}

Henry Chrystyn has no shares in any pharmaceutical companies. He has received sponsorship to carry out studies, together with some consultant agreements and honoraria for presentation, from several pharmaceutical companies that market inhaled products. These include AstraZeneca, Boehringer Ingelheim, GlaxoSmithKline, Innovata Biomed, Meda, Napp Pharmaceuticals, Teva, Trinity Chiesi, Truddell and UCB. Research sponsorship has also been received from grant awarding bodies (EPSRC and MRC).

David Price has consultant arrangements with, Aerocrine, Boehringer Ingelheim, Dey Pharmaceuticals, GlaxoSmithKline, Merck, Sharpe and Dohme, Novartis, Schering-Plough and Teva. He or his team have received grants and research support for research in respiratory disease from the following organisations: UK National Health Service, Aerocrine, AstraZeneca, Boehringer Ingelheim, GlaxoSmithKline, Merck, Sharpe and Dohme, Novartis, Pfizer, Schering Plough and Teva. He has spoken for: Boehringer

\section{References}

1. http://www.sign.ac.uk/guidelines/fulltext/63/index.html. Accessed 6th January 2009.

2. http://www.ginasthma.com/GuidelinesResources.asp?|1=2\&/2=0 Accessed 6th January 2009

3. Anderson HR, Gupta R, Strachan DP, Limb ES. 50 years of asthma: UK trends from 1955 to 2004. Thorax 2007;62:85-90. http://dx.doi.org/10.1136/ thx.2006.066407

4. Rabe KF, Vermeire PA, Soriano JB, Maier WC. Clinical management of asthma in 1999: the Asthma Insights and Reality in Europe (AIRE) study. Eur Respir J 2000; 16:802-07

5. Watson L, Turk F, James P, Holgate ST. Factors associated with mortality after an asthma admission: A national United Kingdom database analysis Respir Med. 2007; 101: 1659-64. http://dx.doi.org/10.1016/j.rmed.2007.03.006

6. Office for National Statistics Mortality Statistics series DH2 no.32 London 2006.

7. Strek ME. Difficult asthma. Proc Am Thorac Soc 2006;3:116-23. http://dx.doi.org/10.1513/pats.200510-115JH

8. Haughney J, Price D, Kaplan A, et al. Achieving asthma control in practice: Understanding the reasons for poor control. Respir Med 2008;102:1681-93. http://dx.doi.org/10.1016/.rmed.2008.08.003

9. Bousquet J, Clark TJ, Hurd S, et al. GINA guidelines on asthma and beyond.
Allergy 2007;62:102-112. http://dx.doi.org/10.1111/j.1398-9995.2006. 01305.x

10. Price $D$, Thomas M. Breaking new ground: challenging existing asthma guidelines. BMC Pulm Med 2006;6(Suppl 1):S6. http://dx.doi.org/10.1186/ 1471-2466-6-S1-S6

11. Dolovich MB, Ahrens RC, Hess DR, et al. Device selection and outcomes of aerosol therapy: Evidence-based guidelines: American College of Chest Physicians/American College of Asthma, Allergy, and Immunology. Chest 2005; 127:335-71. http://dx.doi.org/10.1378/chest.127.1.335

12. Brocklebank D, Ram F, Wright J, et al. Comparison of the effectiveness of inhaler devices in asthma and chronic obstructive airway disease: a systematic review of the literature. Health Technology Assessment 2001;5(20):1-149.

13. Hoskins G, McCowan C, Neville RG, Thomas GE, Smith B, Silverman S. Risk factors and costs associated with an asthma attack. Thorax 2000;55:19-24. http://dx.doi.org/10.1136/thorax.55.1.19

14. Cates CJ, Crilly JA, Rowe BH. Holding chambers (spacers) versus nebulisers for beta-agonist treatment of acute asthma. Cochrane database Syst Rev 2006, 2. http://dx.doi.org/10.1002/14651858.CD000052.pub2

15. Mazhar SHR, Ismail NE, Newton DAG, Chrystyn H. Relative lung deposition of salbutamol following inhalation from a spacer and a Sidestream jet nebuliser following an acute exacerbation. Brit J Clin Pharmacol 2008;65:334-7. http://dx.doi.org/10.1111/j.1365-2125.2007.03036.x

16. McCowan C, Neville RG, Hoskins G. An academic, pharmaceutical and practice collaboration to implement asthma guidelines. Prim Care Resp J 2005;14:10611. http://dx.doi.org/10.1016/j.pcrj.2004.10.008

17. Guest JF, Davie AM, Ruiz FJ, Greener MJ. Switching asthma patients to a oncedaily inhaled steroid improves compliance and reduces healthcare costs. Prim Care Resp J 2005; 14:88-98. http://dx.doi.org/10.1016/j.pcrj.2005.01.002

18. Rau JL. Determinants of patient adherence to an aerosol regimen. Respir Care 2005; 50:1346-56.

19. Horne R. Compliance, adherence, and concordance: implications for asthma treatment. Chest 2006;130(1 Suppl):65S-72S. http://dx.doi.org/10.1378/ chest.130.1_suppl.65S

20. Onyirimba F, Apter A, Reisine $S$, et al. Direct clinician-to-patient feedback discussion of inhaled steroid use: its effect on adherence. Ann Allergy Asthma Immunol 2003;90:411-15.

21. Lenney J, Innes JA, Crompton GK. Inappropriate inhaler use: assessment of use and patient preference of seven inhalation devices. Respir Med 2000;94:496500. http://dx.doi.org/10.1053/rmed.1999.0767

22. Chrystyn H, Corrado OJ, Brownlee K, et al. Inhalation rates of asthmatic children (CHILD) and adults and of chronic obstructive pulmonary disease (COPD) patients through inhalers. Am J Resp Crit Care Med 2002;165(8):A190, 2002.

23. Hanania NA, Wittman R, Kesten $S$, Chapman KR. Medical personnel's knowledge of and ability to use inhaling devices. Metered-dose inhalers, spacing chambers, and breath-actuated dry powder inhalers. Chest 1994;105: 111-16.

24. Giraud $V$ and Roche N. Misuse of corticosteroid metered-dose inhaler is associated with decreased asthma stability. Eur Resp J 2002;19:246-51.

25. Rau JL. Practical problems with aerosol therapy in COPD. Respir Care 2006;51: 158-72.

26. Rau JL. The Inhalation of Drugs: Advantages and Problems. Respir Care 2005; 50:367-82.

27. Crompton GK. Problems patients have using pressurized aerosol inhalers. Eur J Respir Dis Supp/ 1982;119:101-04.

28. Rönmark $E$, Jögi $R$, Lindqvist $A$, et al. Correct use of three powder inhalers: comparison between Diskus, Turbuhaler, and Easyhaler. J Asthma 2005;42: 173-8. http://dx.doi.org/10.1081/JAS-200054629

29. Al-Showair RAM, Pearson SB, Chrystyn H. The potential of a 2tone trainer to help patients use their metered-dose inhalers. Chest 2007;131:1776-82. 
http://dx.doi.org/10.1378/chest.06-2765

30. Newman SP, Weisz AW, Talaee N, Clarke SW. Improvement of drug delivery with a breath actuated pressurised aerosol for patients with poor inhaler technique. Thorax 1991;46:712-16.http://dx.doi.org/10.1136/thx.46.10.712

31. Newman SP, Pavia D, Garland N, Clarke SW. Effects of various inhalation modes on the deposition of radioactive pressurized aerosols. Eur J Respir Dis Suppl. 1982;119:57-65

32. Slader CA, Reddel HK, Spencer LM, et al. Double blind randomised controlled trial of two different breathing techniques in the management of asthma. Thorax 2006;61(8):651-6. http://dx.doi.org/10.1136/thx.2005.054767

33. Minai BA, Martin JE, Cohn RC. Results of a physician and respiratory therapist collaborative effort to improve long-term metered-dose inhaler technique in a pediatric asthma clinic. Respir Care 2004;49:600-05

34. Price D, Thomas M, Mitchell G, Niziol C, Featherstone R. Improvement of asthma control with a breath-actuated pressurised metered dose inhaler (BAl): a prescribing claims study of 5556 patients using a traditional pressurised metred dose inhaler (MDI) or a breath-actuated device. Respir Med 2003;97: 12-19. http://dx.doi.org/10.1053/rmed.2002.1426

35. Mazhar SHRA, Chrystyn H. Salbutamol relative lung and systemic bioavailability of large and small spacers. I Pharm Pharmacol 2008;60:1609-13. http://dx.doi.org/10.1211/jpp/60.12.0006

36. Chrystyn $\mathrm{H}$. Is inhalation rate important for dry powder inhalers? Using the InCheck Dial to identify these rates. Resp Med 2003;97:181-7. http://dx.doi.org/10.1053/rmed.2003.1351

37. Everard ML, Devadason SG, Le Souef PN. Flow early in the inspiratory manoeuvre affects the aerosol particle size distribution from a Turbuhaler. Respir Med 1997;91(10):624-28. http://dx.doi.org/10.1016/S09546111(97)90009-3

38. Svartengren K, Lindestad P, Svartengren M, Philipson, Bylin G and Camner P. Added external resistance reduces oropharyngeal deposition and increases lung deposition of aerosol particles in asthmatics. Am J Respir Crit Care Med 1995;152:32-7.

39. Pedersen S, Steffensen G. Fenoterol powder inhaler technique in children: influence of respiratory flow rate and breath-holding. Eur J Respir Dis 1986;68: 207-14

40. Pedersen S, Frost L, Arnfred T. Errors in inhalation techniques and efficiency in inhaler use in asthmatic children. Allergy 1986;41:118-24. http://dx.doi.org/10.1111/j.1398-9995.1986.tb00287.x

41. Pedersen S. Inhaler use in children with asthma. Dan Med Bull 1987;34:23449.

42. Broeders ME, Molema J, Vermue NA, Folgering HTM. Peak inspiratory flow rate and slope of the inhalation profiles in dry powder inhalers. Eur Respir J 2001;
18:780-3

43. Clark A. Effect of powder inhaler resistance upon inspiratory profiles in health and disease. Respiratory Drug Delivery IV 1994;117-23.

44. Vanden Burgt JA, Busse WW, Martin RJ, Szefler SJ. Donnell D. Efficacy and safety overview of a new inhaled corticosteroid, QVAR (hydrofluoroalkanebeclomethasone extrafine inhalation aerosol) in asthma. J Allergy Clin Immunol 2000;106(6):1209-26. http://dx.doi.org/10.1067/mai.2000.111582

45. Busse WW, Brazinsky S, Jacobson $\mathrm{K}$, et al. Efficacy response of inhaled beclomethasone diproprionate in asthma is proportional to dose and is improved by formulation with a new propellant. J Allergy Clin Immunol 1999; 104(6):1215-22. http://dx.doi.org/10.1016/S0091-6749(99)70016-3

46. Leach CL, Davidson PJ, Hasselquist BE, Boudreau RJ. Influence of particle size and patient dosing technique on lung deposition of HFA-beclomethasone from a metered dose inhaler. J Aerosol Med 2005;18:379-85. http://dx.doi.org/10.1089/jam.2005.18.379

47. Leach CL, Bethke TD, Boudreau RJ, et al. Two-dimensional and threedimensional imaging show ciclesonide has high lung deposition and peripheral distribution: a nonrandomized study in healthy volunteers. J Aerosol Med 2006;19:117-26. http://dx.doi.org/10.1089/jam.2006.19.117

48. Fabbri LM, Nicolini G, Oliveri D, Papi D. Inhaled beclometasone dipropionate/ formoterol extra-fine fixed combination in the treatment of asthma: evidence and future perspectives. Expert Opin Pharmacother 2008;9:479-90. http://dx.doi.org/10.1517/14656566.9.3.479

49. Usmani OS, Biddiscombe MF, Barnes PJ. Regional lung deposition and bronchodilator response as a function of beta-2 agonist particle size. Am J Respir Crit Care Med 2005;172:1497-504. http://dx.doi.org/10.1164/ rccm.200410-14140C

50. Gabrio BJ, Stein SW, Velsaquez DJ. A new method to evaluate plume characteristics of hydrofluoroalkane and chlorofluorocarbon metered dose inhalers. Int J Pharm 1999;186:3-12. http://dx.doi.org/10.1016/S03785173(99)00133-7

51. Shim C, Williams $\mathrm{MH}$. The adequacy of inhalation of aerosol from canister nebulizers. Am J Med 1980;69:891-4. http://dx.doi.org/10.1016/S00029343(80)80016-7

52. Hamid Q, Song $Y$, Kotsimbos TC, et al. Inflammation of small airways in asthma. J Allergy Clin Immunol 1997;100:44-51. http://dx.doi.org/ 10.1016/S0091-6749(97)70193-3

53. Leach CL, Davidson PJ, Hasselquist E, Boudreau RJ. Lung deposition of hydrofluoroalkane-134a beclomethasone is greater than that of chlorofluorocarbon fluticasone and chlorofluorocarbon beclomethasone. Chest 2002;122:510-16. http://dx.doi.org/10.1378/chest.122.2.510

\section{Available online at http://www.thepcrj.org}

